ТРЕБОВАНИЯ К УНИВЕРСАЛЬНОМУ ПРОПАШНОМУ УМНОМУ ТРАКТОРУ

DOI: $10.31618 /$ ESU.2413-9335.2019.4.62.108

Михеев Владимир Васильевич,

канд.техн. наук, ведущций спецчиалист;

Еремин Петр Александрович, научный сотрудник;

Пономарев Андрей Григорьевич,

вед. научн. сотрудник, канд. техн. наук

Федеральный научный агроинженерный чентр ВИМ

2. Москва, Российская Федерачия.

UDC:631.372

\title{
REQUIREMENTS FOR UNIVERSAL TILLED SMART TRACTOR
}

Mikheev Vladimir Vasilievich, Ph.D.(Eng.), leading specialist,; Eremin Peter Aleksandrovich, research assistant;

Ponomarev Andrey Grigorievich, key research engineer, Ph.D.(Eng.). Federal Scientific Agro- Engineering Center VIM, Moscow, Russian Federation.

\section{АННОТАЦИЯ.}

(Цель) Обоснование конструктивной схемы, типа движителя и технологических требований к универсальному умному трактору, используемого на возделывании пропашных, овощных и др. культур. (Материалы и методы) Использованы аналитический и аналоговый подходы: сопоставление исследуемой сущности с существующими в сельском хозяйстве обеспечением тракторами и условиями производства пропашных культур, на примере, сахарной свеклы. (Результаты и обсуждение) Анализ конструкций универсально - пропашных тракторов показал, что создание универсально-пропашных тракторов классов 2-3 интегральной схемы, необходимо выполнить с учетом современных технологических требований производства пропашных культур, имеющихся конструктивных наработок по тракторам типа ЛТЗ155 и Т-70С, мировых тенденций по применению сменных резино - армированных ходов на тракторах и достигнутого технического уровня в оснащении тракторов элементами автоматизации и интеллектуализации. Создаваемые тракторы должны отвечать определенным эксплуатационным требованиям, базирующимся на научно обоснованных свойствах и показателях. (Bblводы) Предложены конструктивная гибридная схема универсально-пропашного трактора интегральной конструкции переменного класса (2-3), достигаемая заменой колесного на гусеничный (резиноармированный) ходовой аппарат, а также оборудованием технологической площадки. Предложены конструктивная гибридная схема универсальнопропашного трактора интегральной конструкции переменного класса (2-3), сформулированы технологические, экологическим и техническим требованиям к умному трактору для возделывании пропашных культур, на примере, сахарной свеклы. Материалы исследования представлены в $3 \mathrm{AO}$ «ПТЗ» г. СанктПетербург.

\section{ANNOTATION.}

(Objective) Justification constructive scheme, vehicle type and technological requirements for universal smart tractor used on tilled cultivation, vegetable, etc. crops. (Materials and methods) Used analytic and analog approaches: comparison of the studied entities with existing agriculture providing tractors and row-crop production conditions, for example, sugar beet. (Results and discussion) Analysis of constructions universally-tractors has shown that the establishment of universally-tractors 2-3 integrated circuit classes, you need to perform to meet modern technological requirements of the production row crops, the existing constructive developments on tractors type LTZ-155 and T-70s, global trends on the use of replaceable rubber-reinforced moves on tractors and technical level of equipment tractors and intellectualization of Automation elements. Created by tractors must meet certain performance requirements, based on scientifically valid properties and values. (Conclusions) Offered constructive hybrid scheme of universally-till tractors of the integral design of alternating class (2-3), which is achieved by a wheeled replacement crawler (rezinoarmirovannyj) running machine, as well as technological equipment playgrounds. Offered constructive hybrid scheme of universally-till tractors of the integral design of alternating class (2-3), technological, environmental and technological requirements for smart tractor for cultivation of cultivated cultures, by example, sugar beet. The study presented in CJSC "BULGE", St.Petersburg

Ключевые слова: требования; технология; экология; трактор; универсально-пропашной; умный; конструктивная схема; сахарная свекла. 
Keywords: methodology, agro-engineering ground, system of intellectual management, production of the cultivated cultures, sugar beet.

Введение и новизна. Производство пропашных тракторов в России имеет тесную связь с проводимой в стране внутренней технической политикой с торговыми союзами, которая зачастую не согласуется с национальными стандартами и специалистами хозяйств [1, с.1]. Так, импорт тракторов превышает собственное производство почти на $50 \%$ и составляет около $76 \%$ от общего количе- ства производимого в нашей стране. Большую часть импорта составляли трактора Беларуси и Казахстана, значительную часть рынка занимают трактора китайского, японского, американского, немецкого и корейского производства (рис.1). Последние, в меньшей мере отвечают технологическим требованиям товаропроизводителей и экологическим стандартам России [2, с.4-8, 3, с.543]. 2014 rop
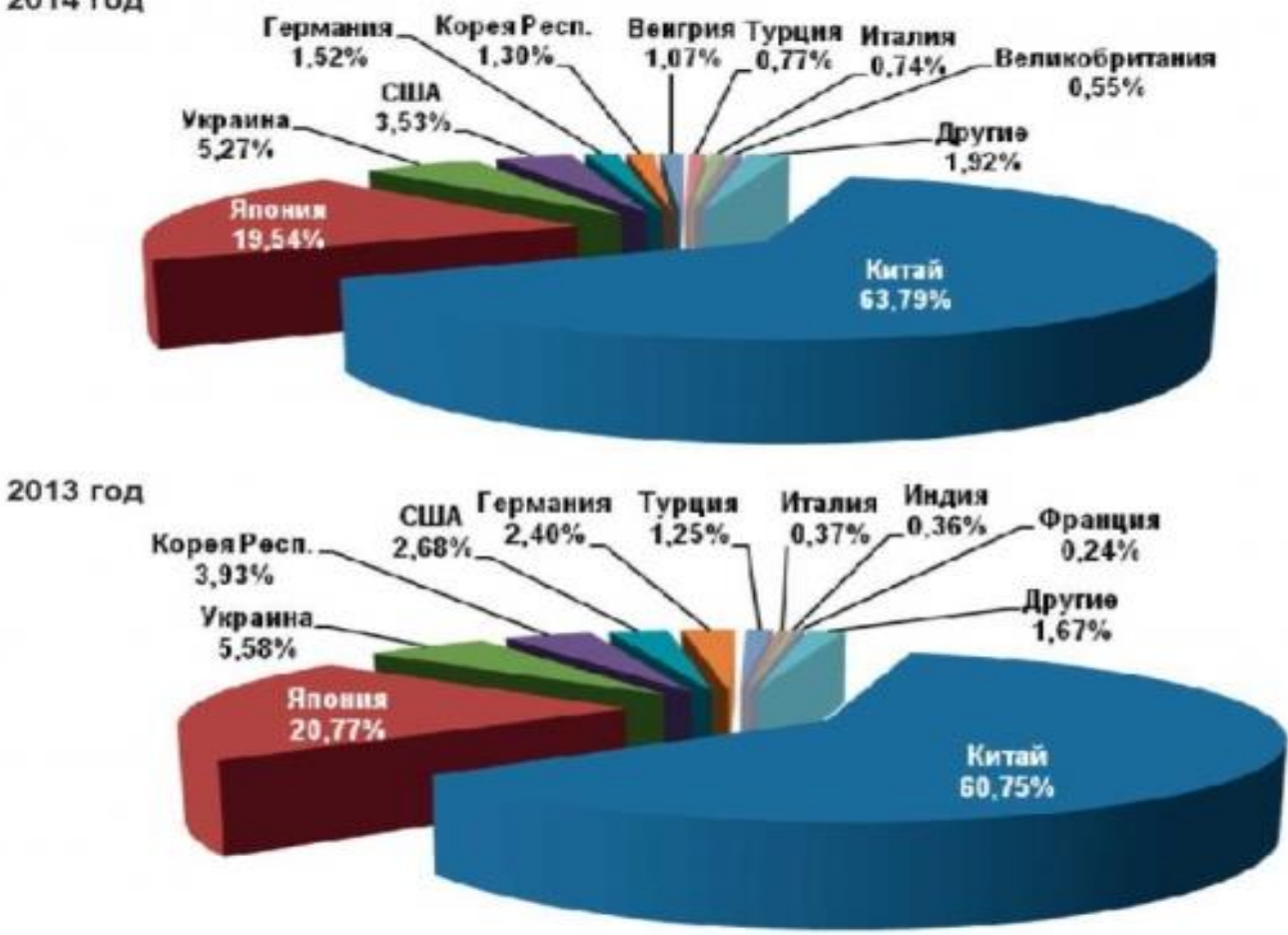

Onеративные данные

Рисунок 1. Структура импорта тракторов в Россию по странам мира

Для обеспечения тракторами собственного производства, в т.ч. и универсально-пропашными, в России принята самостоятельная Государственная программа, рассчитанная до 2020-2025г.г. [4, с. 322], что позволит, в перспективе, создать трактора с новыми потребительскими свойствами, в т.ч. и предлагаемыми ниже.

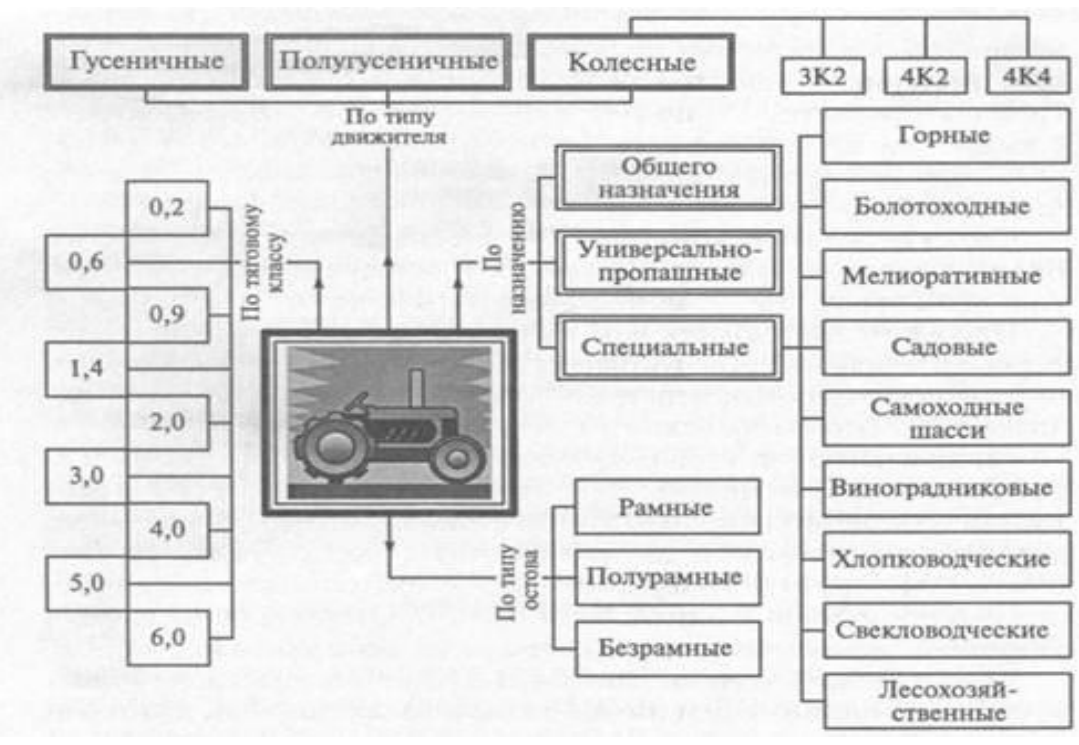


Материалы и методы. Анализ показал, что универсально-пропашные тракторы составляли порядка $50 \%$ от общего количества в парке и классифицируются по назначению (рис.2). По типу движителей они подразделены на колесные и гусеничные. Колесная формула для тракторов этого типа 4К4.

Рисунок 2. Классификация тракторов производимых в России

Наибольшее применение, например, в свекловодстве, имели трактора класса 1,4, 2 и 3. В настоящее время их производство с нужными технологическими и техническими характеристиками не восстановлено, что сдерживает развитие свеклосахарного, овощного и др. видов производств [5, c.64-65, 6, с.18-22].

Так, например, в компоновочных схемах тракторов поступающих в хозяйства отсутствует гибридная схема универсально-пропашного трактора и самоходного энергосредства, которая позволила бы расширить сферу применения имеющихся тракторов на сельскохозяйственных работах, а сельскохозяйственные навесные машины облегчить, за счет снятия с них оборудования для удобрений, гербицидов и семян. Эта схема была реализована при разработке первых образцов трактора ЛТ3-145, которая создавалась на серьезной научной базе [4, с.322]:

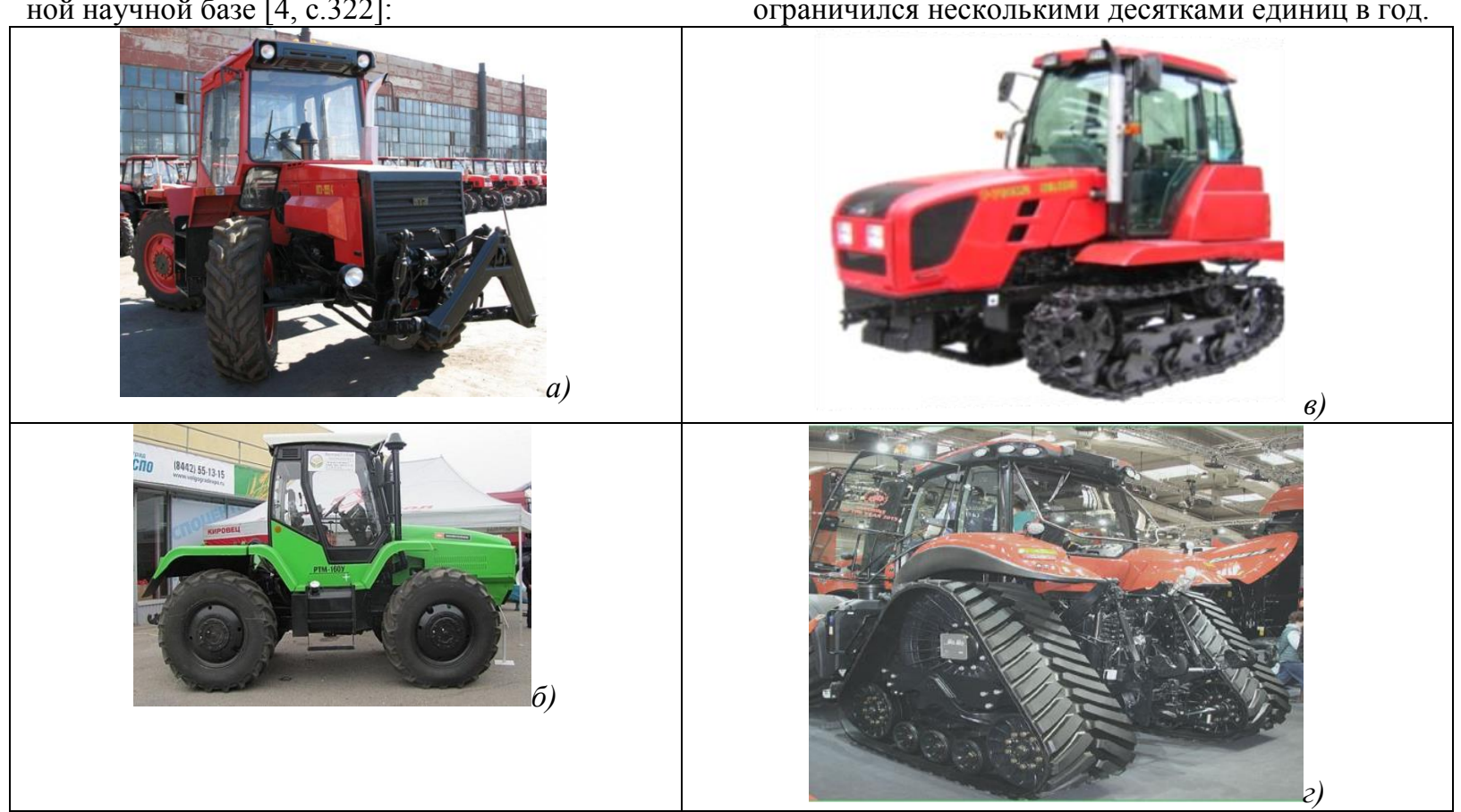

Рисунок 3. Образиь тракторов аналогов и нового поколения:

а) - трактор ЛТ3-155; б) - трактор РТМ-160; в) - трактор T-70С;

г) - трактор Magnuт $380 \mathrm{CVX}$ с резиноармированным ходом

Параллельно с ЛТЗ-155 был воссоздан пропашной гусеничный трактор Т-70С, который ранее широко применялся в хозяйствах на возделывании и уборке пропашных и технических культур (рис.3 в). Он был востребован из-за своих преимуществ по сравнению с колесными тракторами: высокой проходимостью и устойчивость рабочего хода, низким давлением на почвы; универсальностью агрегатирования и маневренностью; широким
- анализе параметров зарубежных прототипов (из ФРГ, США, Италии, Швеции по 11 параметрам) и выборе предпочтительного варианта;

- всесторонней оценке компоновочных схем агрегатирования и использования трактора в народном хозяйстве по 9 схемам при: изменении колеи, ширины шин; применения механических приводов ВОМ; количества гидравлических портов; схем и количества ведущих колес; рабочих скоростей движения; устойчивости при копировании поверхности рельефа поля и дорог; возможности сдваивания колес для снижения давления на почву; возможности навески жидкостного оборудования; мощностных и весовых характеристик и др. К концу 80-х годов уже был создан и запущен в производство (на Липецком тракторном заводе) образец универсально-пропашного трактора интегральной

схемы под маркой ЛТ3-155, который широко начал применяться в сельском хозяйстве, в т.ч. и в свекловодстве (рис. 3 а) [7, с.60]. В постперестроечный

период, к концу 2000г., на АО «Уралвагонзавод» был воссоздан прообраз такого трактора под маркой РТМ-160, однако в его конструкции не нашли воплощение главные отличительные признаки трактора ЛТ3-155 (рис.3 б), а выпуск его ограничился несколькими десятками единиц в год. 
тора интегральной схемы на современном техническом уровне, воплощающим в себя преимущества тракторов типа ЛТ3-155 и Т-70С.

Результаты и обсуждение. Анализ показал, что традиционно различают колесный тип движителей и гусеничный [8, с.12]. Первый тип в исполнении $2 \times 2,2 \times 4$ и т.п., в единичном или спаренном виде, является самым распространенным. Он обеспечивает необходимую тягу, позволяет работать на большой рабочей и транспортной скорости, не повреждает дорожные покрытия, прост в эксплуатации, надежен в работе. Но у таких движителей имеются два существенных недостатка: переуплотнение почвы, что приводит к увеличению защитных зон при уходе за пропашными культурами и наличия буксования колес. Эти признаки приводят к отрицательным экологическим последствиям (образованию пылеватых частиц и эрозии почвы).

Обычный (типовой) металлический гусеничный ход не имеет указанных выше недостатков, но весьма металлоемок, рабочие скорости ограничены до 6-8 км/ч, менее надежен в эксплуатации, повреждает дорожное покрытие, при поворотах и разворотах разрушает верхний почвенный слой, неэффективен на транспортных работах. Зато давление на почву у него в 2-3 раза меньше (до 0,35мПа) чем у колесного хода. Там, где нужна хорошая проходимость агрегата, низкое давление на почву и устойчивость хода, применяют гусеничные движители, в других случаях, на хозяйственных работах - колесные.

В мировой практике появились новые гусеницы - резиноармированные, которые получают все большее распространение. Они еще не отработаны в деталях для пропашных тракторов, но уже сейчас вобрали в себя все лучшее, что есть у колесного хода и обыкновенного гусеничного (рис.3 г). Скорость агрегата на резиноармированном гусеничном движителе доходит до 60 км/ч, гарантируется минимальное давление на почву, гусеницы не повреждают дороги, бесшумны в работе. Оборудование такими гусеницами всей мобильной сельхозтехники может значительно повысить ее общий технический уровень и оптимизировать все эксплуатационные характеристики. В сочетании с независимым реверсивным электро или гидроприводом гусениц, достигается колоссальный эффект по мобильности агрегата, маневренности, сокращению ширины поворотных полос, уменьшению времени на транспортные переезды и т.п.

Исходя из вышеизложенного, создание универсально-пропашных тракторов классов 2-3 интегральной схемы, необходимо выполнить с учетом современных технологических требований производства пропашных культур, имеющихся конструктивных наработок по тракторам типа ЛТЗ155 и Т-70С, мировых тенденций по применению сменных резино - армированных ходов на трактоpax и достигнутого технического уровня в оснащении тракторов элементами автоматизации и интеллектуализации [9, с.63].
Таким образом, создаваемые тракторы должны отвечать определенным эксплуатационным требованиям, базирующимся на научно обоснованных свойствах и показателях. К числу этих требований относятся, прежде всего, высокая производительность и экономичность, выполнение всего комплекса сельскохозяйственных работ качественно, в наилучшие агротехнические сроки. Важное значение имеют требования агроэкологического характера, связанные с загрязнением окружающей среды вредными компонентами, содержащимися в выхлопных газах двигателей, воздействием ходовых систем на почву и др. Ходовая часть уплотняет почву, что отрицательно влияет на ее плодородие и урожайность культур. Поэтому снижение отрицательного воздействия тракторов на почву — одно из важнейших эксплуатационных требований.

Производительность трактора, работающего в агрегате с рабочими машинами, зависит от их ширины захвата, мощности тракторного двигателя, тягового сопротивления машин, тип ходовой системы, средней скорости движения машиннотракторного агрегата (МТА), количества совмещаемых операций, выполняемых навесными машинами и других факторов. Кроме того, производительность зависит от степени утомляемости тракториста, которая, в свою очередь, зависит от плавности хода трактора, защищенности кабины от шума, вибрации, газов, пыли и температуры окружающей среды, легкости управления и обслуживания, обзорности кабины, т. е. от так называемых эргономических свойств тракторов и требований по технике безопасности. Эти требования определяют условия труда тракториста и обслуживающего персонала. Возможность тракторного агрегата совмещать ряд технологических операций, потребует создание условий для автоматизации операций контроля и оперативного управления многими рабочими процессами, т.е. интеллектуализации.

Требования, направленные на обеспечение высокой производительности трактора, должны выполняться совместно с агротехническими требованиями к выполняемым работам. Эти требования взаимосвязаны. Технологические требования, предъявляемые к универсально-пропашным тракторам класса 2-3 можно свести к следующему [10, c.20]:

1. возделывание сахарной и кормовой свеклы и др. пропашных и овощных культур, включая их семенники, с междурядьями - 45, 60, 70, 75 и $90 \mathrm{~cm}$;

2. компоновочные схемы должны обеспечивать комбинированное агрегатирование с бесприводными и приводными сельхозмашинами на передней и задней навесных системах, а технологические емкости для семян, удобрений и средств защиты растений, на технологической площадке трактора;

3. низкое давление ходовых систем на почву в период полевых работ не более $80 \ldots 210$ кПа (по ГОСТ 26955-86 Техника сельскохозяйственная 
мобильная. нормы воздействия движителей на почву), путем их смены, с колесной на резиноармированную;

4. использование ходовой системы с минимальным радиусом поворота на поле, не менее продольной базы агрегата;

5. автосцепные устройства и средства для наблюдения за их положением должны позволять обслуживать агрегат одному трактористу, как в поле, так и при агрегатировании навесных маши, с массой $2 \ldots 3$ тонны, так и прицепных;

6. обеспечение проходимости машин по наиболее типичным почвам и в междурядьях пропашных культур, возделываемых на ровной, гребневой и грядовой поверхности поля; клиренс, регулируемый $30 \ldots 50 \mathrm{~cm}$; агротехнический просвет элементов навески не менее $27 . .45 \mathrm{~cm}$; применение ботвоотводов для колес (по заказу);

7. обеспечиваемая защитная зона ходового аппарата от рядка растений при работе в междурядьях не менее 30...50мм;

8. качественное выполнение технологических процессов путем: стабилизации рабочих скоростей (минимальная - 0,74...2,85 км/ч для рассадных работ); частоты вращения ВОМ; авторегулирования глубины хода навесных машин; автонаправления/автовождения по рядкам растений, с точностью не менее 2-3см; высокая обзорность рабочего поля; видимость бортового монитора и доступность управления компьютером и операциями; беспроводная связь с современными гаджетами;

9.использование в конструкции гидростанций или электрогенераторов для привода технологических агрегатов и машин;

10. технический уровень создаваемого перспективного умного трактора должен соответствовать современным и будущим тенденциям развития техники и сельскохозяйственного производства и, в частности, интеллектуализации управления рабочими процессами и роботизации, с контролем протоколов работы и передачи данных по Wi-Fi, iPhone или Skype.

Выводы. Предложены конструктивная гибридная схема универсально-пропаш-ного трактора интегральной конструкции переменного класса (2-3), достигаемая заменой колесного на гусеничный (резиноармированный) ходовой аппарат, а также оборудованием его технологической площадкой. Сформулированы технологические, экологическим и техническим требованиям к умному трактору для возделывании пропрашных культур, на приме, сахарной свеклы. Материалы исследования представлены в ЗАО «ПТЗ» г. СанктПетербург. (Mihail.Lebedev@sptz.kzgroup.ru).

\section{Список литературы.}

1 Прохоров А. В Удмуртии будут выпускать интегральные тракторы // Soya News. Электронный ресурс: http://www: SoyaNews: Новости рынка кормов .soyanews.infosЛента новостей $>$ index.php?FILTER=Y. - C. 1.09.12. 2016; 14:08
2. Нефедов А. Производство и рынок сельскохозяйственных тракторов в России в 2017 году.//Основные средства. 2018. N10. - С. 4-8.

3. Россия в цифрах. 2016. Крат. стат. сб./Росстат. М., 2016. - 543 с.

4. Дурманов А.С. Далекое прошлое и недавнее будущее... из истории создания тракторов интегральной схемы в России. Липецк: ООО «Липецкая Печатная Компания». 2014. - 322 с.

5. Алексеев К.И. Повышение экономической эффективности формирования и использования технической базы производства сахарной свеклы (на материалах Орловской обл.). Дис. на соиск. канд. эконом. наук, М.: ФГБНУ ВНИИЭСХ, 2014. - C.64-65.

6. Ревякин Е.Л. Эффективность ресурсосберегающих технологий в растениеводстве / Е.Л. Ревякин // Техника и оборудование для села. 2013. N 9. - C. 18-22.

7. Михеев В.В., Халилуллин Р.В., Кусова Н.И., Кривогов Н.И., Евтюшенков Н.Е., Алдохин В.Г., Бармина И.П. (ВИМ) и др. Низкозатратные технологии и комплексы машин для производства сахарной и кормовой свеклы. М.: Информагротех. 1999. -60 c.

8. Жалнин Э.В., Хорт Д.О. Мировые тенденции технического прогресса в АПК//Аграрное обозрение. 2016, N3.- С. 12

9. Нунгезер В.В., Сорокин Н.Т.,. Гоголев Г.А., Федоренко В.Ф., Табашников А.Т., Буклагин Д.С., Аронов Э.Л., Гольтяпин В.Я., , Марченко Р.А., Измайлов А.Ю., Елизаров В.П., Ерохин М.Н., Левшин А.Г., Иванов Ю.А., , Цой Л.М. Технические и технологические требования к сельскохозяйственной технике и оборудованию, используемым в растениеводстве и животноводстве, с учетом зональных условий М.: ВИМ, 2010. - 63 с.

10. Бычков Н.И., Михеев В.В., Кривогов Н.И. О выборе типа трактора для свекловодства//Сахарная свекла. 2001. N7. - С.20.

\section{References}

1 Prokhorov A.B. In Udmurtia will produce integral tractors//Soya News. Electronic resource: http://www: SoyaNews: market news feed. soyanews.info > news > index.php? Filter $=\mathrm{Y}$-s. 1.09.12. 2016; 14:08.

2. Nefedov A. production and market agricultural tractors in Russia in the year 2017.//fixed assets. 2018. The N10. - pp. 4-8.

3. Russia in figures. 2016. Ratio. STAT. sat../Rosstat. M., 2016. - 543 p.

4. Durmanov A.S. Distant past and recent future ... from the history of the integrated circuit of tractors in Russia. Lipetsk: Moscow Printing Company. 2014.$322 \mathrm{p}$.

5. Alexeev K.I. Increasing economic efficiency of formation and use of technical base of sugar beet production (on materials of Orlovskoy oblast). Dees. at soisk. Cand. economy. Sciences, M.: FGBNU VNIIESH, 2014. -p.p. 64-65.

6. Revyakin E.L. Resourcesaving technologies Efficiency in crop production/E.L. 
Revyakin//Machinery and equipment for the village. 2013 N 9. - p.p. 18-22.

7. V.V Mikheev, R.V. Halilullin, N.I.Kusova, N.I.Krivogov, N.E.Evtjushenkov, V.G. Aldohin, I.P.Barmina, (WIM), Etc. Low-cost technologies and complex of machines for the production of sugar and fodder beet. M.: Informagroteh. 1999. $-60 \mathrm{p}$.

8. Zhalnin E.V., Hort D.O. World tendencies of technological progress in agriculture//Agricultural review. 2016, N3.-.p. 12.
9. Nungeiser V.V., Sorokin N.T., Gogolev G.A., Fedorenko V.F., Tabashnikov A.T., Buklagin D.S., Aronov E.1., Goltjapin V.Y., Marchenko, R.A., Izmailov A.Y., Elizarov V.P., Yerokhin M.N., Levshin A.G., Ivanov, Y.A., Tsoy L.M. Technical and technological requirements for agricultural machinery and equipment used in crop and livestock production, with zonal m. conditions: WIM, 2010. $-63 \mathrm{p}$.

10. Bychkov N.I., Mikheev V.V., Krivogov N.I. On choosing the type of tractor for sveklovodstva//Sugar beet. 2001. N7. - p. 20.

\title{
ВОЗДЕЛЫВАНИЕ МОРКОВИ В ЛЕТНЕМ ПОСЕВЕ В УСЛОВИЯХ ОРОШЕНИЯ НИЖНЕГО ДОНА
}

\author{
Гурина Ирина Владимировна \\ д.с.-х.н., профессор кафедры мелиорачии земель \\ Новочеркасского инженерно-мелиоративного института им. А.К. Кортунова \\ ФГБОУ ВО Донской государственный аграрный университет, \\ Россия, г. Новочеркасск \\ Михеев Николай Васильевич \\ к.с.-х.н., профессор кафедры мелиораиии земель \\ Новочеркасского инженерно-мелиоративного института им. А.К. Кортунова \\ ФГБОУ ВО Донской государственный аграрный университет, \\ Россия, г. Новочеркасск \\ Коржов Виктор Иванович \\ к.т.н., профессор кафедры мелиораиии земель \\ Новочеркасского инженерно-мелиоративного института им. А.К. Кортунова \\ ФГБОУ ВО Донской государственный аграрный университет, \\ Россия, г. Новочеркасск
}

\section{АННОТАЦИЯ}

Рассмотрены особенности возделывания моркови в летнем посеве на землях центральной орошаемой зоны Нижнего Дона. Изучена агротехника, сроки и нормы посева, уходные работы и режимы орошения моркови в летнем посеве.

\section{ABSTRACT}

Peculiarities of summer planted carrot cultivation on the lands of central irrigated zone of Lower Don are considered. Agricultural technique, terms and planting norms, maintenance and carrot irrigation modes are studied.

Ключевые слова: морковь, летний посев, сроки сева, нормы высева, обработка почвы, возделывание, вегетация растений моркови, вегетационный полив, урожайность.

Key words: carrot, summer planting, planting terms, seeding rate, soil cultivation, tillage, vegetation, vegetation watering, yield productivity.

Морковь среди всех столовых корнеплодов возделываемых в нашей стране является наиболее полезнейшим овощем, содержащим значительное количество витаминов и аминокислот.

Морковь была известна ещё древним грекам под названием «даукос», и сохранилась в Греции этом понятии до настоящих дней. Современное русское название овоща - морковь - имеет общие корни с аналогичным названием в болгарском, сербском, польском, шведском и немецком языках.

Морковь - ценнейший источник каротина для человека. В 100 г сырой массы моркови содержится 22 г каротина, который в организме человека перерабатывается в витамин А. В ней содержатся витамины группы В, Е, К, РР, аскорбиновая кислота, многие минеральные вещества, особенно калий и органические кислоты. Морковь широко используется в качестве компонента при изготовлении различных консервов, первых и вторых блюд, салатов [1]. Морковный сок - витаминизированный продукт, хорошо усваиваемый организмом человека, применяемый для лечебных целей.

Морковь является двулетним растением, в первый год образует розетку листьев и корнеплод, а во второй год жизни - семенной куст и семена. Морковь относится к холодостойким растениям, семена прорастают при температуре почвы $+4 \ldots+5$ ${ }^{0} \mathrm{C}$, всходы легко переносят заморозки до $-3{ }^{0} \mathrm{C}$. При высоких температурах, в особенности при недостатке влаги, прекращается рост и развитие, снижаются вкусовые качества корнеплодов.

Морковь лучше растет и развивается на легких суглинистых и супесчаных почвах, хуже - на тяжелых глинистых, с неглубоким пахотным слоем, Она является хорошим предшественником для других овощных культур, но её размещают на вто- 